\title{
Mating system variation in the hermaphroditic brooding coral, Seriatopora hystrix
}

\author{
$\mathrm{CDH}$ Sherman \\ Institute for Conservation Biology, School of Biological Sciences, University of Wollongong, Wollongong, New South Wales, Australia
}

\begin{abstract}
Self-compatible, hermaphroditic marine invertebrates have the potential to self-fertilize in the absence of mates or under sperm-limited conditions, and outcross when sperm is available from a variety of males. Hence, many hermaphroditic marine invertebrates may have evolved mixed-mating systems that involve facultative self-fertilization. Such mixedmating strategies are well documented for plants but have rarely been investigated in animals. Here, I use allozyme markers to make estimates of selfing from population surveys of reef slope and reef flat sites, and contrast this with direct estimates of selfing from progeny-array analysis, for the brooding coral Seriatopora hystrix. Consistent heterozygote deficits previously reported for $S$. hystrix suggests that inbreeding (including the extreme of selfing) may be common in this species. I detected significant levels of inbreeding within
\end{abstract}

populations $\left(F_{\mathrm{IS}}=0.48\right)$ and small but significant differentiation among all sites $\left(F_{\mathrm{ST}}=0.04\right)$. I detected no significant differentiation among habitats $\left(F_{\mathrm{HT}}=0.009\right)$ though among site differentiation did occur within the reef slope habitat $\left(F_{\mathrm{SH}}=0.06\right)$, but not within the reef flat habitat $\left(F_{\mathrm{SH}}=0.015\right)$. My direct estimates of outcrossing for six colonies and their progeny from a single reef flat site revealed an intermediate value $\left(t_{\mathrm{m}} \quad( \pm \mathrm{s} . \mathrm{d})=.0.53 \pm 0.20\right)$. Inbreeding coefficients calculated from progeny arrays $\left(F_{\mathrm{e}}=0.31\right)$ were similar to indirect estimates based on adult genotype frequencies for that site $\left(F_{I S}=0.38\right)$. This study confirms that the mating system of this brooding coral is potentially variable, with both outcrossing and selfing.

Heredity (2008) 100, 296-303; doi:10.1038/sj.hdy.6801076; published online 7 November 2007

Keywords: self-fertilization; outcrossing; mixed-mating system; reproductive assurance; genetic subdivision; sperm limitation

\section{Introduction}

Reproduction through exclusive self-fertilization appears rare for the majority of hermaphroditic plants and animals, however, it is becoming increasingly clear that mating systems where a proportion of progeny are outcrossed and the remaining are selfed are an important reproductive strategy in some groups (reviewed in Jarne and Charlesworth, 1993; Knowlton and Jackson, 1993; Goodwillie et al., 2005). Despite the potential for selffertilized progeny to have lower fitness than outcrossed progeny due to inbreeding depression (Shields, 1982; Grosberg, 1987; Hunter and Hughes, 1993; Shields, 1993; Hoare and Hughes, 2001), the selective advantage of being able to self-fertilize is obvious; under conditions where outcross fertilization cannot occur, either due to the complete absence of mates or under gamete limitation, self-fertilization provides the opportunity for reproductive assurance (Goodwillie et al., 2005; Henry et al., 2005; Jarne and Auld, 2006). Additionally, it has been argued that self-fertilization may also allow for the purging of deleterious recessive alleles within a population, thereby reducing the possible costs of inbreeding (Shields, 1982, 1993; Lande and Schemske, 1985; Lande

Correspondence: Dr CDH Sherman, Institute for Conservation Biology, School of Biological Sciences, University of Wollongong, Wollongong, New South Wales 2522, Australia.

E-mail: csherman@uow.edu.au

Received 1 August 2007; revised 3 October 2007; accepted 9 October 2007; published online 7 November 2007 et al., 1994; Hedrick and Kalinowski, 2000). Current understanding of the evolutionary and ecological significance of self-fertilization versus outcrossing is mainly derived from investigation of terrestrial plant species (reviewed in Jarne and Charlesworth, 1993; Hedrick and Kalinowski, 2000; Goodwillie et al., 2005). The importance of such mating systems in animals has, however, rarely been investigated (reviewed in Jarne and Auld, 2006), though information on the importance of selfing in pulmonate snails (Jarne and Charlesworth, 1993; Jarne et al.,1996, 2000; Trouvé et al., 2003; Henry et al., 2005), ascidians (Ryland and Bishop, 1990; Bishop and Ryland, 1993; Cohen, 1996; Jiang and Smith, 2005; Manríquez and Castilla, 2005) and platyhelminthes (Trouvé, et al., 1996) is starting to emerge.

In hermaphroditic marine species that reproduce by broadcast spawning (that is, shedding of male and female gametes into the water column), or brooding species that rely on the movement of sperm between individuals (spermcast species; Bishop and Pemberton, 2006), the rapid dilution and relatively short lifespan of sperm means that outcrossed fertilization is proximity dependent (Grosberg, 1987; Babcock et al., 1994; Levitan and Petersen, 1995; Coffroth and Lasker, 1998). While some plants have evolved associations with pollinators to assist in the transfer of pollen from one individual to another, no such associations are known for marine taxa. Although pheromones and other chemotactic attractants may be used by some marine taxa to increase fertilization success (for example, Coll et al., 1995; Riffell et al., 2002, 2004), and despite the potential for decreased fitness due 
to inbreeding through selfing, the capacity to ensure fertilization in the absence of potential mates or under sperm-limited conditions means that self-fertilization may be an important reproductive tactic for hermaphroditic brooding and broadcast spawning species (for example, Sabbadin, 1971; Heyward and Babcock, 1986; Stoddart et al., 1988; Yund and McCartney, 1994; Cohen, 1996, Brazeau et al., 1998).

The largely hermaphroditic scleractinian corals provide a good model to test the importance of selffertilization in marine invertebrates (reviewed in Carlon, 1999). These reef-building corals display a diverse range of reproductive strategies that include sexual and asexual modes, hermaphroditic and gonochoristic species and broadcast spawning and internal brooding modes of fertilization (Harrison and Wallace, 1990). Surprisingly, however, little is known about selfing rates within coral species, though studies of the population structure of a number of species suggest that inbreeding, including the extreme of selfing may be important (for example, Ayre and Dufty, 1994; Brazeau et al., 1998; Ayre and Hughes, 2000; Goffredo et al., 2004). In vitro fertilization trials have been carried out to determine the extent of self-compatibility for a number of broadcast spawning species (Heyward and Babcock, 1986; Stoddart et al., 1988; Willis et al., 1997; Baums et al., 2005) and have been informative about the potential for selfing within some species. However, direct estimates of selfing rates for both brooding and broadcast spawning species are needed to assess the importance of selfing within natural populations. This is more easily accomplishable for brooding species whose larvae can easily be collected and their genotypes compared to the maternal colony.

In this study I use co-dominant allozyme markers to determine the population structure and mating system for the hermaphroditic, brooding coral, Seriatopora hystrix collected from One Tree Island, on the southern Great Barrier Reef, Australia. Mating system parameters were assessed by making indirect estimates of the levels of inbreeding within populations using fine-scale genetic surveys and comparing these to direct estimates made from progeny arrays and surrounding adult genotype frequencies.

\section{Materials and methods}

\section{Adult and larval collections}

I made collections of adult $S$. hystrix from three sites $\left(\sim 25 \mathrm{~m}^{2}\right)$ in each of two reef habitats, the reef slope (7-11 $\mathrm{m}$ depth) and reef flat (0-2 $\mathrm{m}$ depth), during November/December 2002 at the One Tree Island Reef $\left(23^{\circ} 30^{\prime} \mathrm{S} ; 152^{\circ} 06^{\prime} \mathrm{E}\right)$ on the southern Great Barrier Reef, Australia. The three sites within each reef habitat were separated by a minimum of $50 \mathrm{~m}$, while the two habitats were separated by approximately $2 \mathrm{~km}$. Sperm dispersal over these scales is unlikely, though Ayre and Miller (2006) suggest that sperm of Acropora palifera may disperse over tens of metres, and sperm dispersal between sites within a habitat may therefore be possible. Each collection consisted of 47-50 fragments $(\sim 2 \mathrm{~cm}$ long) taken haphazardly from available colonies, and representing most of the adult colonies within each site. Samples were frozen in liquid nitrogen prior to transportation back to the laboratory, where they were stored at $-80^{\circ} \mathrm{C}$ until needed for electrophoresis.

For larval collections, I removed 15 adult colonies $(>8 \mathrm{~cm}$ diameter) from the reef flat (site 3) and transported them to the laboratory in sea water. Colonies were held in separate aquaria with flow through sea water pumped directly from the reef lagoon through a sand filter. A control aquarium, which did not contain a coral colony, was used to determine if water pumped in from the reef lagoon contained coral larvae that may confound my results. I detected no coral larvae within the control aquarium during the experimental period. Six of the 15 colonies released larvae (up to 85 larvae per colony) over an 11-day period. I collected larvae either in overflow traps lined with plankton mesh $(200 \mu \mathrm{m}$ pore diameter), or siphoned them off the bottom of each aquarium. Genotypes of larvae and the brood parent were determined by allozyme electrophoresis within $24 \mathrm{~h}$ of larval release.

\section{Electrophoresis}

Previous population genetic studies of S. hystrix on the Great Barrier Reef have shown that certain allozyme loci are highly variable and provide a useful marker system to assess population structure and mating system in this species (for example, Ayre and Dufty, 1994; Ayre and Hughes, 2000). Tissue extracts and electrophoresis methods were the same as those described by Ayre and Dufty (1994). Electrophoresis was carried out on horizontal starch gels $(12 \% \mathrm{w} / \mathrm{v})$ using a tris citrate (TC8), tris-EDTA-borate (TEB) or tris-maleate (TM) buffer modified from Selander et al. (1971). A total of eight enzyme loci were consistently resolvable. These included glucosephosphate isomerase (Gpi, EC 5.3.1.9); malate dehydrogenase (Mdh1E2, EC 1.1.1.37) assayed on TC8; hexokinase (Hk, EC 2.7.1.1); phosphoglucomutase (Pgm2, EC 5.4.2.2) assayed on TM; leucyl-proline peptidase ( $L p p$, EC 3.4.11) and leucyl-glycyl glycyl peptidase (Lgp1E2, EC 3.4.11) assayed on TEB. Between three and six alleles were detected at each locus, and alleles were described numerically in order of decreasing electrophoretic mobility. Due to their small size ( $\sim 400 \mu \mathrm{m}$ diameter; Baird and Babcock, 2000), larvae could only be assayed on a single buffer system (TC8) and, therefore, were only scored for Gpi, Mdh1, Mdh2 and $H k$ to maximize the number of loci scored. Mdh1 was invariable in the site from which broods were collected and, therefore, was excluded from progeny-array analysis.

\section{Statistical analysis}

Genetic variation and adult population structure: I tested the statistical power of the marker system to assess the population structure and mating system by calculating the probability of identity, $P_{\mathrm{ID}}$, for increasing locus combinations (Waits et al., 2001) using the program GenAlex (V6) (Peakall and Smouse, 2006). P ID was calculated as:

$$
P_{I D}=\sum p_{i}+\sum \sum\left(2 p_{i} p_{j}\right)
$$

where $p_{i}$ and $p_{j}$ are the frequencies of the $i$ th and $j$ th alleles and $i \neq j$ (Paetkau and Strobeck, 1994). This identification $\left(P_{\mathrm{ID}}\right)$ estimator calculates the probability that two individuals drawn at random from a population will have the same genotype at multiple loci and is used 
to access the statistical confidence of the marker system for individual identification. $P_{\text {ID }}$ was calculated for each locus using adult allele frequencies in the population and then multiplied across loci to give an overall $P_{\text {ID }}$ (Waits et al., 2001).

Asexual reproduction is a common reproductive strategy in many coral species and will influence estimates of population structure and mating system (for example, Ayre and Hughes, 2000; Billingham et al., 2003; Baums et al., 2005). I therefore assessed the importance of asexual reproduction within my populations by first comparing the number of colonies sampled $(N)$ to the number of unique multi-locus genotypes $\left(N_{\mathrm{g}}\right)$ detected. I then compared the ratio of observed multilocus genotypic diversity $\left(G_{\mathrm{o}}\right)$ to that expected under conditions of sexual reproduction with free recombination $\left(G_{\mathrm{e}}\right)$, as described by Stoddart and Taylor (1988). Departures of $G_{\mathrm{o}} / G_{\mathrm{e}}$ from unity should reflect the combined effects of departures from single-locus Hardy-Weinberg equilibrium, and of multi-locus linkage disequilibrium. Such departures may result from factors, such as inbreeding, population subdivision and asexual reproduction. If these departures result from inbreeding, then this should lead to significant heterozygote deficits across all loci screened. If, however, departures are due to asexual reproduction, this should lead to both significant deficits and excess of heterozygotes across different loci (Stoddart and Taylor, 1988). In contrast, a population with complete random mating will display a $G_{\mathrm{o}} / G_{\mathrm{e}}$ ratio of close to unity. The statistical significance of differences between $G_{0}$ and $G_{e}$ was then assessed by determining if $G_{\mathrm{o}}$ lay outside the $95 \%$ confidence interval (CI) of $G_{e}$ (Stoddart and Taylor, 1988). To reduce the chance of type I errors a sequential Bonferroni correction was then applied.

As clonal reproduction may influence estimates of population structure and mating system parameters, all analyses and data presented were calculated using only unique multi-locus genotypes. To ensure that each locus behaved independently, I tested each pairwise combination of loci for linkage disequilibrium for each site (168 tests) using the program GENEPOP V3.4 (Raymond and Rousset, 1995). I then assessed the effects of inbreeding on population structure by calculating the magnitude and direction of departures from Hardy-Weinberg equilibria within each site for each locus. Departures were expressed as a fixation index, $f$ (Wright, 1978), where positive and negative values represent deficits or excesses of heterozygotes, respectively. For those loci that were sufficiently variable (that is, frequency of the most common allele $<95 \%$; Hedrick, 2000), I determined significant departures from Hardy-Weinberg equilibrium using exact tests implemented in the program GENEPOP V3.4 (Raymond and Rousset, 1995). A sequential Bonferroni correction was then applied to reduce the chance of type I errors (Rice, 1989). Differences in $f$ among sites and habitats were assessed by a two-way ANOVA with sites nested within habitat. For each site, the overall inbreeding coefficient $\left(F_{\text {IS }}\right)$ was calculated using the formulations of Weir and Cockerham (1984) using the program FSTAT (Goudet, 2002).

I used a hierarchical analysis of standardized genetic variance $(F)$ statistics (Wright, 1969) to partition genetic variation among sites, and between habitats. Subscripts were used to denote the source of variation: $F_{\text {IS, variation }}$ among individuals within a site; $F_{\mathrm{ST}}$, total variation among all sites; $F_{\mathrm{SH}}$, variation among sites within habitats and $F_{\mathrm{HT}}$, total variation between habitats. Parameters were calculated using the formulations of Weir and Cockerham (1984) using the program FSTAT (Goudet, 2002), which executes numerical re-sampling to provide estimates of variances across loci (jack-knifing). Values of $F$ were judged to be statistically significant when 0 lay outside the $95 \%$ CI of the bootstrapped mean.

\section{Mating system parameters}

I calculated outcrossing rates and other mating system parameters using the multi-locus mating program MLTR (Ritland, 2002). Larval and maternal genotypes, and those of neighbouring adult colonies from the reef flat (site 3) were used to calculate the following mating system parameters: (1) single $\left(t_{\mathrm{s}}\right)$ and multi-locus $\left(t_{\mathrm{m}}\right)$ outcrossing rates (where $t=1$ for complete outcrossing and $t=0$ for complete self-fertilization); (2) the rate of biparental inbreeding $\left(t_{\mathrm{m}}-t_{\mathrm{s}}\right)$ which gives a measure of the degree of mating among close relatives and (3) the correlation of outcrossed paternity among progeny of the same mother (that is, the likelihood that a randomly chosen pair of progeny from a single mother share the same father, $r_{\mathrm{p}}$ ). These mating system parameters were calculated using the Newton-Raphson iteration, and 1000 bootstrap replicates were performed to obtain standard deviations (s.d.) for each parameter. If the mating system is at equilibrium, direct estimates of the inbreeding coefficient can be calculated from outcrossing estimates using the relationship $F_{\mathrm{e}}=\left(1-t_{\mathrm{m}}\right) /\left(1+t_{\mathrm{m}}\right)$ (Hedrick, 2000).

\section{Results}

\section{Allelic variation}

I detected high levels of variability within each of the six sites sampled, with three to six alleles detected at each locus (mean \pm s.e. $=4.25 \pm 1.04$ ). Allele frequencies for each site are available in Supplementary Table 1. The eight allozyme loci allowed a high degree of discrimination among genotypes within each site, as indicated by the probability of identity, $P_{\mathrm{ID}}$, ranging from 0.002 to $<0.001$ when all eight loci are included (Table 1). The expected number of individuals that might display the same multi-locus genotype within each population, as a consequence of random mating, was therefore low, providing a high degree of resolution in detecting any contribution of asexual reproduction within these populations. Additionally, $P_{\mathrm{ID}}$ for the three loci used to genotype brooded larvae was low $\left(P_{\mathrm{ID}}=0.014\right.$ for reef flat site 3), indicating a high level of power (98\%) in identifying genotypes derived from identity by descent (Table 1). Thus, it is likely that of the 237 larvae, up to five may have been misidentified.

\section{Genotypic diversity}

Generally, all collections contained approximately the levels of multi-locus genotypic diversity expected for sexual reproduction (Table 2). The proportion of unique genotypes $\left(N_{\mathrm{g}}\right)$ to the number of colonies sampled $(N)$ was consistently high across all sites with $N_{\mathrm{g}} / N$ ranging from 0.84 to 0.96 (Table 2). While I did detect some replicate genotypes within sites, these were represented 
Table 1 The probability of identity, $P_{\mathrm{ID}}$, for increasing locus combinations, calculated for the brooding coral Seriatopora hystrix from six reef sites

\begin{tabular}{|c|c|c|c|c|c|c|c|c|}
\hline & \multicolumn{8}{|c|}{$\mathrm{P}_{I D}$ for increasing locus combinations } \\
\hline & Gpi1 & $+H k$ & $+M d h 2$ & $+M d h 1$ & $+P g m$ & $+\operatorname{Lgg1}$ & $+L g 2$ & $+L p$ \\
\hline \multicolumn{9}{|l|}{ Reef flat } \\
\hline Site 1 & 0.215 & 0.057 & 0.023 & 0.023 & 0.018 & 0.003 & 0.002 & $<0.001$ \\
\hline & & 0.072 & 0.025 & & 0.015 & 0.0 & 0.001 & $<0$ \\
\hline Site 3 & 0.210 & 0.043 & 0.014 & 0.013 & 0.007 & 0.002 & 0.001 & $<0.0$ \\
\hline \multicolumn{9}{|c|}{ Reef slope } \\
\hline & 0.161 & 0.028 & 0.009 & 0.007 & 0.003 & $<0.001$ & $<0.001$ & $<0.001$ \\
\hline & 0.2 & 0.119 & 0.0 & 0.0 & 0.042 & 0.014 & 0.005 & 0.002 \\
\hline Site 3 & 0.257 & 0.058 & 0.019 & 0.017 & 0.008 & 0.001 & $<0.001$ & $<0.00$ \\
\hline
\end{tabular}

$P_{\text {ID }}$ calculates the probability that two individuals drawn at random from a population will have the same genotype at multiple loci and is used to assess the statistical confidence for individual identification (Waits et al., 2001).

Table 2 Comparison of the observed and expected multi-locus genotypic diversity for Seriatopora hystrix from three sites $\left(25 \mathrm{~m}^{2}\right)$ within each of two reef habitats from the One Tree Island Reef Great Barrier Reef, Australia

\begin{tabular}{cccccccc}
\hline \multicolumn{1}{c}{$N$} & $N_{g}$ & $N_{g} / N$ & $G_{o}$ & $G_{e}$ (s.d.) & $G_{o} / G_{e}$ & $P$ \\
\hline Reef flat & & & & & & & \\
Site 1 & 47 & 43 & 0.91 & 40.16 & $44.52(2.77)$ & 0.90 & $>0.05$ \\
Site 2 & 48 & 44 & 0.92 & 41.90 & $44.40(3.10)$ & 0.94 & $>0.05$ \\
Site 3 & 50 & 48 & 0.96 & 46.30 & $48.20(2.61)$ & 0.96 & $>0.05$ \\
& & & & & & & \\
Reef slope & & & & & & & \\
Site 1 & 47 & 43 & 0.91 & 38.75 & $46.72(1.13)$ & 0.83 & $<0.001$ \\
Site 2 & 48 & 41 & 0.85 & 33.88 & $41.38(4.55)$ & 0.82 & $>0.05$ \\
Site 3 & 50 & 42 & 0.84 & 32.89 & $47.82(2.87)$ & 0.69 & $<0.001$ \\
\hline
\end{tabular}

$N$, number of individual colonies sampled; $N_{g}$, number of unique multi-locus genotypes detected, $G_{0}$, observed multi-locus genotypic diversity; $G_{e}$, multi-locus genotypic diversity expected for random mating. Significant departures of $G_{\mathrm{o}}$ from $G_{\mathrm{e}}$ were determined using unpaired $t$-tests and applying a sequential Bonferroni correction for simultaneous tests.

by only two or three individuals and no single genotype was numerically dominant within any given site (Supplementary Table 2). Within sites, S. hystrix showed between 69 and $96 \%$ of the genotypic diversity expected for sexual reproduction $\left(G_{\mathrm{o}} / G_{\mathrm{e}}=0.69-0.96\right.$; Table 2$)$. These high levels of genotypic diversity suggest that predominately sexually derived recruits maintain these populations, however, I did detect significant deviations from expectations for random mating for two reef slope sites (Table 2). However, the consistent heterozygote deficits detected across all eight loci within these sites (Table 3) suggests that these departures are likely the result of inbreeding, rather than asexual reproduction via fragmentation which should result in both deficits and excess across different loci.

\section{Adult population structure}

Tests for linkage disequilibria revealed 65 interlocus associations in a total of 168 pairwise tests, however, there was no consistent pattern of linkage between loci, and none of these associations remained significant after
Table 3 Fixation index (f; Wright (1978)) and significant departures from levels of heterozygosity expected under Hardy-Weinberg equilibrium for Seriatopora hystrix from three sites $\left(25 \mathrm{~m}^{2}\right)$ within each of two reef habitats from the One Tree Island Reef, Great Barrier Reef, Australia

\begin{tabular}{lccccccc}
\hline Locus & \multicolumn{3}{c}{ Reef flat } & & \multicolumn{3}{c}{ Reef slope } \\
\cline { 2 - 3 } \cline { 7 - 8 } & Site 1 & Site 2 & Site 3 & & Site 1 & Site 2 & Site 3 \\
\hline Gpi & 0.14 & 0.19 & 0.07 & & $0.29^{* * *}$ & -0.03 & 0.29 \\
Hk & 0.05 & 0.16 & $0.27^{*}$ & & 0.27 & $0.47^{* *}$ & $0.58^{* * *}$ \\
Mdh1 & - & $1.00^{\mathrm{a}}$ & $1.00^{\mathrm{a}}$ & & 0.55 & $-0.01^{\mathrm{a}}$ & $-0.02^{\mathrm{a}}$ \\
Mdh2 & $0.50^{* *}$ & $0.58^{* * *}$ & $0.48^{* * *}$ & & $0.77^{* * *}$ & $0.46^{* * *}$ & $0.51^{* * *}$ \\
Pgm2 & 0.28 & 0.19 & 0.08 & & $0.95^{* * *}$ & $1.00^{\mathrm{a}}$ & $0.84^{* * *}$ \\
Lggp1 & $0.53^{* *}$ & 0.28 & 0.27 & & $0.67^{* * *}$ & $0.32^{* *}$ & $0.47^{* * *}$ \\
Lggp2 & $0.54^{* *}$ & $0.73^{* * *}$ & $0.74^{* * *}$ & & $0.49^{* *}$ & $1.00^{* * *}$ & $1.00^{* * *}$ \\
Lpp & $1.00^{* * *}$ & $0.87^{* * *}$ & $0.79^{* * *}$ & & $0.70^{* * *}$ & $0.84^{* * *}$ & $0.88^{* * *}$ \\
$F_{\mathrm{IS}}$ & 0.41 & 0.41 & 0.38 & & 0.55 & 0.52 & 0.58
\end{tabular}

Significant departures determined after the application of a sequential Bonferroni correction. ${ }^{*} P<0.05$, ${ }^{* *} P<0.01$, ${ }^{* * *} P<0.001$. $F_{\mathrm{IS}}$, overall inbreeding coefficient for each site.

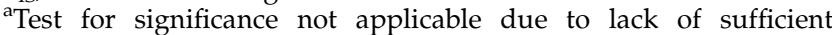
variation at this site (Hedrick 2000)

application of a sequential Bonferroni correction. In 36 of 42 valid tests across eight loci, estimates of single-locus heterozygosity were significantly different from expectations for Hardy-Weinberg equilibrium (Table 3). All departures represented heterozygote deficits, 28 of which remained significant after the application of a sequential Bonferroni correction, indicating the probable effects of inbreeding and/or self-fertilization (Table 3). I detected no significant differences in the mean inbreeding coefficients among sites within either of the two habitats $\left(\mathrm{F}_{4,35}=0.29, P=0.88\right)$, though I did detect significantly higher levels of inbreeding within the reef slope compared with the reef flat habitat $\left(F_{1,35}=5.12, P=0.03\right)$.

Analysis of standardized genetic variance, $F$ (Wright, 1978), revealed significant levels of population subdivision among sites $\left(F_{\mathrm{ST}}=0.04 \pm 0.01\right.$ s.e., $95 \%$ $\mathrm{CI}=0.051-0.031)$ but little differentiation between habitats $\left(F_{\mathrm{HT}}=0.009 \pm 0.01\right.$ s.e., $95 \% \mathrm{CI}=0.015$ to -0.013$)$ (Table 4). Interestingly, I detected high and significant levels of genetic differentiation between sites from the reef slope habitat $\left(F_{\mathrm{SH}}=0.06 \pm 0.01\right.$ s.e., $95 \% \mathrm{CI}=0.080$ $0.044)$, however, levels of genetic differentiation among sites from the reef flat habitat were not significantly different from $0\left(F_{\mathrm{SH}}=0.015 \pm 0.01\right.$ s.e., $95 \% \mathrm{CI}=0.031$ to $-0.001)$. The mean inbreeding coefficient for all sites indicated a significant degree of inbreeding and/or selfing, as reflected by the large and consistent heterozygous deficits across all loci $\left(F_{\mathrm{IS}}=0.48 \pm 0.09\right.$ s.e., $95 \%$ $\mathrm{CI}=0.65-0.34)$.

\section{Mating system}

The brooded larvae of S. hystrix (237 larvae from six adult colonies) all showed the presence of at least one maternal allele at each locus, as expected for Mendelian inheritance (see Supplementary Table 2 for genotypic frequencies). However, the presence of non-maternal alleles in some larvae indicates that broods were sexually produced. Estimates of the mean multi-locus outcrossing rate were intermediate $\left(t_{\mathrm{m}}=0.53 \pm 0.20 \mathrm{~s}\right.$.d.), suggesting a moderate level of self-fertilization within these broods. 
Table 4 Hierarchical analysis of standardized genetic variation calculated using the formula of Weir and Cockerham (1984) for Seriatopora hystrix from three sites $\left(25 \mathrm{~m}^{2}\right)$ within each of two reef habitats from the One Tree Island Reef, Great Barrier Reef, Australia

\begin{tabular}{|c|c|c|c|c|c|}
\hline \multirow[t]{2}{*}{ Locus } & \multirow[t]{2}{*}{$F_{\text {IS }}$} & \multirow[t]{2}{*}{$F_{\mathrm{ST}}$} & \multirow[t]{2}{*}{$F_{\mathrm{HT}}$} & \multicolumn{2}{|c|}{$F_{\mathrm{SH}}$} \\
\hline & & & & Reef flat & Reef slope \\
\hline Gpi & 0.211 & 0.038 & 0.020 & 0.018 & 0.029 \\
\hline$H k 1$ & 0.283 & 0.028 & 0.005 & 0.004 & 0.061 \\
\hline$M d h 1$ & 0.547 & 0.021 & 0.004 & -0.001 & 0.010 \\
\hline$M d h 2$ & 0.586 & 0.005 & 0.001 & -0.009 & 0.068 \\
\hline $\operatorname{Pgm} 1$ & 0.606 & 0.055 & 0.014 & 0.011 & 0.084 \\
\hline Lgp1 & 0.426 & 0.038 & 0.010 & 0.033 & 0.040 \\
\hline Lgp2 & 0.732 & 0.068 & 0.001 & 0.058 & 0.119 \\
\hline Lpp & 0.822 & 0.050 & 0.023 & -0.012 & 0.062 \\
\hline Mean ( \pm s.e.) & $0.480(0.09)$ & $0.040(0.01)$ & $0.009(0.01)$ & $0.015(0.01)$ & $0.060(0.01)$ \\
\hline $95 \%$ CI & 0.652 to 0.340 & 0.051 to 0.031 & 0.015 to -0.013 & 0.031 to -0.001 & 0.080 to 0.044 \\
\hline
\end{tabular}

$F_{\mathrm{IS}}$, variation among individuals (i.e., inbreeding coefficient); $F_{\mathrm{ST}}$, variation among all sites; $F_{\mathrm{HT}}$, variation among habitats and $F_{\mathrm{SH}}$, variation among sites within a habitat.

However, standard deviations were relatively large, and individual colony outcrossing rates varied from $<1$ to $98 \%$ indicating large variability among individual broods. The mean single-locus estimates of outcrossing were slightly lower than multi-locus estimates $\left(t_{\mathrm{s}}=0.51 \pm 0.20 \mathrm{s.d}.\right)$. Consequently, estimates of biparental inbreeding were relatively low, but were significantly different from $0 \quad\left(t_{\mathrm{m}}-t_{\mathrm{s}}=0.03 \pm 0.02\right.$ s.d. $)$, suggesting that at least some outcrossing events occur between closely related individuals. The estimation of correlated paternity (that is, the likelihood that a randomly chosen pair of progeny from a single mother share the same father) was highly variable and did not differ from $0\left(r_{\mathrm{p}}=0.34 \pm 0.24 \mathrm{~s} . \mathrm{d}\right.$.), indicating that multiple sires may contribute to the same brood (Ritland, 2002). The equilibrium inbreeding coefficient $\left(F_{\mathrm{e}}=0.31\right)$ calculated from $t_{\mathrm{m}}$ was similar to the observed inbreeding coefficient $\left(F_{\text {IS }}=0.38\right)$ (Table 3$)$ for this site, suggesting that the mating system of $S$. hystrix may be near equilibrium with respect to inbreeding and selection against selfed individuals.

\section{Discussion}

These results confirm that the hermaphroditic brooding coral S. hystrix displays mating system variation characterized by almost equal levels of outcrossing and selfing. This type of mating system parallels the mixedmating strategy reported for an increasing number of plants (reviewed in Goodwillie et al., 2005) and supports predictions that despite the potential for decreased fitness of offspring due to severe inbreeding depression (Shields, 1982), the ability of assuring fertilization in the absence of potential mates, or under sperm-limited conditions (for example, Levitan and Petersen, 1995, though see Yund, 2000), means that self-fertilization is likely to be an important mode of reproduction in some brooding marine animals (Shields, 1982; Knowlton and Jackson, 1993).

My results confirm and extend Ayre and Resing's (1986) findings that $S$. hystrix broods are sexually produced. Moreover, the levels of selfing detected in this study are consistent with previous reports of large heterozygote deficiencies in populations of $S$. hystrix from two other studies along the Great Barrier Reef (Ayre and Dufty, 1994; Ayre and Hughes, 2000). Heterozygote deficits are a common feature of many marine populations and are often presented as evidence in support of mating systems characterized by high levels of inbreeding and/or selfing (Ayre and Dufty, 1994; Edmands and Potts, 1997; Viard et al., 1997; Ayre and Hughes, 2000, 2004; Reusch, 2001; Goffredo et al., 2004). Nevertheless, other potential factors may contribute to heterozygote deficits, for example, selection against heterozygotes (Borsa et al., 1992), the presence of null alleles (Foltz, 1986; Ayre et al., 1997), and the inadvertent sampling of multiple genetic subpopulations with differing allele frequencies (that is, the Wahlund effect, Hedrick, 2000). In this study, my estimate of the inbreeding coefficient from adult allele frequencies within reef flat site 3 $\left(F_{\mathrm{IS}}=0.38\right)$, are similar to that calculated directly from outcrossing rates for the same site $\left(F_{\mathrm{e}}=0.31\right)$. This implies that levels of self-fertilization and biparental inbreeding could themselves be sufficient to explain most of the heterozygote deficits detected in adult populations, and that the Wahlund effect accounts for little of the observed heterozygote deficits (though see Ayre and Dufty, 1994).

Overall estimates of inbreeding across all six sites in this study (average $F_{\mathrm{IS}}=0.48$ ) were similar to the values previously reported by Ayre and Dufty (1994) and Ayre and Hughes (2000) ( $F_{\mathrm{IS}}=0.23$ and 0.51 , respectively). Interestingly, I detected higher levels of inbreeding and genetic subdivision among sites within the reef slope habitat compared with the reef flat habitat. This is consistent with Ayre and Dufty's (1994) finding of higher levels of inbreeding within the reef slope habitat compared with either the lagoon or reef flat habitat. These habitats differ in a number of important aspects that may affect levels of inbreeding and genetic differentiation. Lower adult densities within the reef slope habitat may result in reduced opportunity for outcrossed fertilization. However, other factors such as larval dispersal and settlement behaviour, and biparental inbreeding are also likely to affect estimates of inbreeding and genetic differentiation within this habitat. In the present study estimates of levels of outcrossing varied markedly among individual colonies, from complete selfing to almost exclusive outcrossing, suggesting that levels of selfing are likely to reflect a facultative strategy dependent on the number of mates available for outcrossing. 
The levels of self-fertilization reported here for S. hystrix are similar to those reported for the broadcast spawning coral Goniastrea favulus (50-65\%) in laboratory fertilizations (Heyward and Babcock, 1986; Stoddart et al., 1988). These levels of selfing are also comparable to those purportedly calculated from randomly amplified polymorphic DNA markers for two Caribbean hermaphroditic brooding coral species, Favia fragum $(49 \%)$ and Porites astreoides (34\%) (Brazeau et al., 1998). However, as cautioned by Brazeau et al. (1998), confidence limits of selfing estimates could not be calculated because their sampling design provided no objective means of predicting the genotypes expected under different mating systems (see Ayre and Miller, 2006).

Interestingly, the levels of self-fertilization detected for $S$. hystrix in this study are in contrast with those reported for the brooding hermaphroditic coral, A. palifera (Ayre and Miller, 2006). In that study, Ayre and Miller (2006) found that broods collected from colonies from two sites (150 and $200 \mathrm{~m}^{2}$ ) were generated almost exclusively by outcrossing $\left(t_{\mathrm{m}}=0.92-0.96\right)$, and that sperm had potentially dispersed over tens of metres. Sperm dispersal over similarly large distances has been reported for brooding ascidians (Yund, 1998). This suggests that there is large inter-specific variation in levels of self-compatibility among brooding species, similar to that previously seen in broadcast spawners (Willis et al., 1997) and plant mating systems (Jarne and Charlesworth, 1993; Hedrick and Kalinowski, 2000; Goodwillie et al., 2005). However, until a greater number of brooding species have been investigated, it remains unclear as to the extent and importance of self-fertilization in brooding corals. Additionally, estimates of the relative fitness and survival of selfed versus outcrossed larvae would be invaluable for making evolutionary inferences on how self-fertilization is maintained within this group.

My analysis of the mating system of $S$. hystrix imply intermediate levels of outcrossing, however, I detected large inter-colony variation in outcrossing rates $(<1-98 \%)$. This variation suggests that rates of selfing of $S$. hystrix may be highly variable, allowing varying levels of selfing depending on the availability of non-self sperm. The availability of non-self sperm may result from a number of factors, including variation in the distance between nearest neighbours, levels of clonality within a population (and hence the opportunity for matings between ramets belonging to the same genet), variation in levels of self-compatibility among individual colonies and variation in local hydrodynamic regimes that affect the dispersal and dilution of gametes. Nevertheless, my direct estimates of outcrossing based on examination of progeny arrays are consistent with indirect measures of the levels of inbreeding based on adult genotype frequencies from two previous studies of S. hystrix on the Great Barrier Reef (Ayre and Dufty, 1994; Ayre and Hughes, 2000). The recent development of highly variable microsatellite markers for a number of brooding (Maier et al., 2001; Magalon et al., 2004) and broadcast spawning (Miller and Howard, 2004) corals will greatly increase the ability of studies to accurately determine levels of outcrossing and inbreeding within this important group of marine invertebrates.

The combination of relatively high levels of selffertilization and highly restricted dispersal of sperm and/or larvae are the likely sources of the high levels of
Mating system variation in a brooding coral $\mathrm{CDH}$ Sherman

inbreeding and genetic subdivision reported in populations of $S$. hystrix along the Great Barrier Reef. This supports a growing body of evidence that indicates that inbreeding and self-fertilization may be important reproductive strategies in many marine and freshwater hermaphroditic species (Grosberg, 1987, 1991; Knowlton and Jackson, 1993; Cohen, 1996; Viard et al., 1997; Carlon, 1999; Jarne et al., 2000; Reusch, 2001) where rapid sperm dilution and low adult densities for sessile organisms or those with restricted mobility suggests selfing may be advantageous (Knowlton and Jackson, 1993). The evolution of facultative rates of selfing in S. hystrix would be consistent with the reproductive-assurance hypothesis, which predicts ecological factors (for example, variation in mate availability and pollen/sperm limitation) would be important in the stabilization of a mixed mating system (Holsinger, 1996). Self-fertilization also occurs in plant species with abiotically pollinated plant mating systems (that is, wind- or water-dispersed pollen), although it appears less common than outcrossing (Goodwillie et al., 2005). This mechanism of gamete dispersal is similar to that seen in brooding marine animals, which rely on sperm dispersal via water currents. However, these systems do vary in fundamentally different ways, which are likely to have important implications for fertilization success. First, pheromones and other chemotactic attractants may be used by some marine animals to increase fertilization success and outcrossing (for example, Coll et al., 1995; Riffell et al., 2002, 2004), while filter feeding species have been shown to actively filter out and store sperm from conspecific individuals (Yund, 2000; Hughes et al., 2002). Nevertheless, levels of selfing may be more common in marine animals than is currently recognized and more research is clearly needed to determine the extent of selffertilization and the factors important in maintaining mixed reproductive strategies.

\section{Acknowledgements}

I thank AM Martin, KJ Miller, C Mundy and J Dunn for help with field and laboratory work. K Beinssen and $P$ Beinssen assisted at the University of Sydney's One Tree Island research station. This work was supported in part by two student grants to CDH Sherman by the Great Barrier Reef Marines Park Authority and by an ARC Discovery grant to DJ Ayre and KJ Miller. I thank DJ Ayre, KJ Miller and three anonymous reviewers for helpful comments on an earlier version of this manuscript.

\section{References}

Ayre DJ, Dufty S (1994). Evidence for restricted gene flow in the viviparous coral Seriatopora hystrix on Australia Great Barrier Reef. Evolution 48: 1183-1201.

Ayre DJ, Hughes TP (2000). Genotypic diversity and gene flow in brooding and spawning corals along the Great Barrier Reef, Australia. Evolution 54: 1590-1605.

Ayre DJ, Hughes TP (2004). Climate change, genotypic diversity and gene flow in reef-building corals. Ecol Lett 7: 273-278.

Ayre DJ, Hughes TP, Standish RS (1997). Genetic differentiation, reproductive mode, and gene flow in the brooding coral Pocillopora damicornis along the Great Barrier Reef, Australia. Mar Ecol Prog Ser 159: 175-187. 
Ayre DJ, Miller KJ (2006). Random mating in the brooding coral Acropora palifera. Mar Ecol Prog Ser 307: 155-160.

Ayre DJ, Resing JM (1986). Sexual and asexual production of planulae in reef corals. Mar Biol 90: 187-190.

Babcock RC, Mundy CN, Whitehead D (1994). Sperm diffusion models and in situ confirmation of long-distance fertilization in the free-spawning asteroid Acanthaster planci. Biol Bull 186: 17-28.

Baird AH, Babcock RC (2000). Morphological differences among three species of newly settled Pocilloporid coral recruits. Coral Reefs 19: 179-183.

Baums IB, Hughes CR, Hellberg ME (2005). Mendelian microsatellite loci for the Caribbean coral Acropora palmata. Mar Ecol Prog Ser 28: 115-127.

Billingham MR, Reusch TBH, Alberto F, Serrao EA (2003). Is asexual reproduction more important at geographical limits? A genetic study of the seagrass Zostera marina in the Ria Formosa, Portugal. Mar Ecol Prog Ser 265: 77-83.

Bishop JDD, Pemberton AJ (2006). The third way: spermcast mating in sessile marine invertebrates. Intergr Compar Biol 46: 398-406.

Bishop JDD, Ryland JS (1993). Enzyme electrophoretic evidence for the prevalence of outcrossing in the hermaphroditic brooding ascidian Dendrodoa grossularia (Chordata, Urochordata). J Exp Mar Biol Ecol 168: 149-165.

Borsa P, Jousselin Y, Delay B (1992). Relationships between allozymic heterozygosity, body size, and survival to natural anoxic stress in the Palourde, Ruditapes decussatus L (Bivalvia, Veneridae). J Exp Mar Biol Ecol 155: 169-181.

Brazeau DA, Gleason DF, Morgan ME (1998). Self-fertilization in brooding hermaphroditic Caribbean corals: evidence from molecular markers. J Exp Mar Biol Ecol 231: 225-238.

Carlon DB (1999). The evolution of mating systems in tropical reef corals. Trends Ecol Evol 14: 491-495.

Coffroth MA, Lasker HR (1998). Larval paternity and male reproductive success of a broadcast-spawning gorgonian, Plexaura kuna. Mar Biol 131: 329-337.

Cohen CS (1996). The effects of contrasting modes of fertilization on levels of inbreeding in the marine invertebrate genus Corella. Evolution 50: 1896-1907.

Coll JC, Leone PA, Bowden BF, Carroll AR, Konig GM, Heaton A et al. (1995). Chemical aspects of mass spawning in corals. II.: epi-thunbergol, the sperm attractant in the eggs of the soft coral Lobophytum crassum (Cnidaria: Octocorallia). Mar Biol 123: $137-143$.

Edmands S, Potts DC (1997). Population genetic structure in brooding sea anemones (Epiactis spp.) with contrasting reproductive modes. Mar Biol 127: 485-498.

Foltz DW (1986). Null alleles as a possible cause of heterozygote deficiencies in the oyster Crassostrea virginica and other bivalves. Evolution 40: 869-870.

Goffredo S, Mezzomonaco L, Zaccanti F (2004). Genetic differentiation among populations of the Mediterranean hermaphroditic brooding coral Balanophyllia europaea (Scleractinia: Dendrophylliidae). Mar Biol 145: 1075-1083.

Goodwillie C, Kalisz S, Eckert CG (2005). The evolutionary enigma of mixed-mating systems in plants: occurrence, theoretical explanations, and empirical evidence. Annu Rev Ecol Syst 36: 47-79.

Goudet J (2002). FSTAT, A Program to Estimate and Test Gene Diversities and Fixation Indices (version 2.9.3.2). Institute of Ecology, University of Lausanne: Switzerland http:// www.unil.ch/izea/softwares/fstat.html.

Grosberg RK (1987). Limited dispersal and proximity dependent mating success in the colonial ascidian Botryllus schlosseri. Evolution 41: 372-384.

Grosberg RK (1991). Sperm-Mediated gene flow and the genetic structure of a population of the colonial ascidian Botryllus schlosseri. Evolution 45: 130-142.

Harrison PL, Wallace CC (1990). Coral Reefs. Ecosystems of the World. Elsevier: Amsterdam.
Hedrick PW (2000). Genetics of Populations, 2nd edn. Jones and Bartlett: Boston.

Hedrick PW, Kalinowski ST (2000). Inbreeding depression in conservation biology. Annu Rev Ecol Syst 31: 139-162.

Henry P-Y, Bousset L, Sourrouille P, Jarne P (2005). Partial selfing, ecological disturbance and reproductive assurance in an invasive freshwater snail. Heredity 95: 428-436.

Heyward AJ, Babcock RC (1986). Self and cross-fertilization in scleractinian corals. Mar Biol 90: 191-196.

Hoare K, Hughes RN (2001). Inbreeding and hermaphroditism in the sessile, brooding bryozoan Celleporella hyalina. Mar Biol 139: $147-162$.

Holsinger KE (1996). Pollination biology and the evolution of mating systems in flowering plants. Evol Biol 29: 107-149.

Hughes RN, Manriquez PH, Bishop JDD (2002). Female investment is retarded pending reception of allosperm in a hermaphroditic colonial invertebrate. Proc Natl Acad Sci USA 99: 14884-14886.

Hunter E, Hughes RN (1993). Self-fertilisation in Celleporella hyalina. Mar Biol 115: 495-500.

Jarne P, Auld JR (2006). Animals mix it up too: the distribution of self-fertilization among hermaphroditic animals. Evolution 60: $1816-1824$

Jarne P, Charlesworth D (1993). The Evolution of the selfing rate in functionally hermaphrodite plants and animals. Annu Rev Ecol Syst 24: 441-466.

Jarne P, Njiokou F, Bellec C, Delay B (1996). Population genetic structure and mating systems in hermaphrodite freshwater snails: the examples of Bulinus globosus and B. truncatus. Malacol Rev Suppl 6: 115-120.

Jarne P, Perdieu MA, Pernot AF, Delay B, David P (2000). The influence of self-fertilization and grouping on fitness attributes in the freshwater snail Physa acuta: population and individual inbreeding depression. J Evol Biol 13: 645-655.

Jiang D, Smith WC (2005). Self- and cross-fertilization in the solitary ascidian Ciona savignyi. Biol Bull 209: 107-112.

Knowlton N, Jackson JBC (1993). Inbreeding and outbreeding in marine invertebrates. In: Thornhill N (ed). The Natural History of Inbreeding and Outbreeding. University of Chicago Press: Chicago. pp 200-249.

Lande R, Schemske DW (1985). The evolution of self-fertilization and inbreeding depression in plants. I. Genetic models. Evolution 39: 24-40.

Lande R, Schemske DW, Schultze ST (1994). High inbreeding depression, selective interference among loci, and the threshold selfing rate for purging recessive lethal mutations. Evolution 48: 965-978.

Levitan DR, Petersen C (1995). Sperm Limitation in the sea. Trends Ecol Evol 10: 228-231.

Magalon H, Samadi S, Richard M, Adjeroud M, Veuille M (2004). Development of coral and zooxanthella-specific microsatellites in three species of Pocillopora (Cnidaria, Scleractinia) from French Polynesia. Mol Ecol Notes 4: 206-208.

Maier E, Tollrian R, Nuernberger B (2001). Development of species-specific markers in an organism with endosymbionts: microsatellites in the scleractinian coral Seriatopora hystrix. Mol Ecol Notes 1: 157-159.

Manríquez PH, Castilla JC (2005). Self-fertilization as an alternative mode of reproduction in the solitary tunicate Pyura chilensis. Mar Ecol Prog Ser 305: 113-125.

Miller KJ, Howard CG (2004). Isolation of microsatellites from two species of scleractinian coral. Mol Ecol Notes 4: 11-13.

Paetkau D, Strobeck C (1994). Microsatellite analysis of genetic variation in black bear populations. Mol Ecol 3: 489-495.

Peakall R, Smouse PE (2006). GenAlEx 6: genetic analysis in Excel. Population genetic software for teaching and research. Mol Ecol Notes 6: 288-295.

Raymond M, Rousset F (1995). GENPOP (version 1.2): population genetics software for exact tests and ecumenicism. J Hered 86: 248-249. 
Reusch TBH (2001). Fitness-consequences of geitonogamous selfing in a clonal marine angiosperm (Zostera marina). J Evol Biol 14: 129-138.

Rice WR (1989). Analyzing tables of statistical tests. Evolution 43: 223-225.

Riffell JA, Krug PJ, Zimmer RK (2002). Fertilization in the sea: the chemical identity of an abalone sperm attractant. $J$ Exp Biol 205: 1439-1450.

Riffell JA, Krug PJ, Zimmer RK (2004). The ecological and evolutionary consequences of sperm chemoattraction. Proc Natl Acad Sci USA 101: 4501-4506.

Ritland K (2002). Extensions of models for the estimation of mating systems using $\mathrm{n}$ independent loci. Heredity 88: 221-228.

Ryland JS, Bishop JDD (1990). Prevalence of cross-fertilization in the hermaphroditic compound ascidian Diplosoma listerianum. Mar Ecol Prog Ser 61: 125-132.

Sabbadin A (1971). Self-fertilization and cross-fertilization in compound ascidian Botryllus schlosseri. Dev Biol 24: 379-391.

Selander RK, Smith MH, Yank SY, Johnston WE, Gentry JB (1971). Biochemical polymorphism and systematics in the genus Peromyscus. I. Variation in the old-field mouse (Peromyscus polionotus). Study in Genetics VI. University of Texas Publications. Austin 7103. pp 49-90.

Shields WM (1982). Philopatry, Inbreeding, and the Evolution of Sex. State University of New York Press: Albany.

Shields WM (1993). The natural and unnatural history of inbreeding and outbreeding. In: Thornhill NV (ed). The Natural History of Inbreeding and Outbreeding: Theoretical and Empirical Perspectives on Population Structure. University of Chicago Press: Chicago. pp 143-169.

Stoddart JA, Babcock RC, Heyward AJ (1988). Self-fertilization and maternal enzymes in the planulae of the coral Goniastrea favulus. Mar Biol 99: 489-494.

Stoddart JA, Taylor JF (1988). Genotypic diversity-Estimation and prediction in samples. Genetics 118: 705-711.
Trouvé S, Degen L, Renaud F, Goudet J (2003). Evolutionary implications of a high selfing rate in the freshwater snail Lymnaea truncatula. Evolution 57: 2303-2314.

Trouvé S, Renaud F, Durand P, Jourdane J (1996). Selfing and outcrossing in a parasitic hermaphrodite helminth (Trematoda, Echinostomatidae). Heredity 77: 1-8.

Viard F, Justy F, Jarne P (1997). The influence of self-fertilization and population dynamics on the genetic structure of subdivided populations: a case study using microsatellite markers in the freshwater snail Bulinus truncatus. Evolution 51: 1518-1528.

Waits LP, Luikart G, Taberlet P (2001). Estimating the probability of identity among genotypes in natural populations: cautions and guidelines. Mol Ecol 10: 249-256.

Weir BS, Cockerham CC (1984). Estimating F-statistics for the analysis of population structure. Evolution 38: 1358-1370.

Willis BL, Babcock RC, Harrison PL, Wallace CC (1997). Experimental hybridization and breeding incompatibilities within the mating systems of mass spawning reef corals. Coral Reefs 16: S53-S65.

Wright S (1969). The Evolution and Genetics of Populations, vol. 2. The Theory of Gene Frequencies. University of Chicago Press: Chicago.

Wright S (1978). Evolution and the Genetics of Populations. IV. Variability Within and Among Natural Populations. University of Chicago Press: Chicago.

Yund PO (1998). The effect of sperm competition on male gain curves in a colonial marine invertebrate. Ecology 79 328-339.

Yund PO (2000). How severe is sperm limitation in natural populations of marine free-spawners? Trends Ecol Evol 15: 10-13.

Yund PO, McCartney MA (1994). Male reproductive success in sessile invertebrates-Competition for fertilizations. Ecology 75: $2151-2167$

Supplementary Information accompanies the paper on Heredity website (http://www.nature.com/hdy) 